Revista Brasileira de Agricultura Irrigada v.10, nº.2, p. 565 - 575, 2016

ISSN 1982-7679 (On-line)

Fortaleza, CE, INOVAGRI - http://www.inovagri.org.br

DOI: $10.7127 /$ rbai.v10n200405

Protocolo 405.16 - 19/02/2016 Aprovado em 14/04/2016

\title{
PRODUTIVIDADE E EFICIÊNCIA DE USO DA ÁGUA EM CULTIVO DE FEIJÃO SOB DIFERENTES COBERTURAS DO SOLO SUBMETIDO À RESTRIÇÃO HÍDRICA
}

\author{
José Edmilson Deodato de Brito ${ }^{1}$, Alexsandro Claudio dos Santos Almeida ${ }^{2}$, Gustavo \\ Bastos Lyra ${ }^{3}$, Ricardo Araujo Ferreira Junior ${ }^{4}$, Iedo Teodoro ${ }^{4}$, José Leonado de Souza ${ }^{4}$
}

\begin{abstract}
RESUMO
O objetivo deste trabalho foi avaliar o efeito da utilização de diferentes coberturas de solo na produtividade e eficiencia de uso da água no cultivo do feijão submetido a restrição hídrica na fase florescimento. O experimento foi conduzido na área experimental de Agrometeorologia da Universidade Federal de Alagoas em delianeamento em blocos ao acaso com fatorial com $3 \mathrm{x}$ 2. Três tipos de manejo do solo: solo coberto com palhada, solo coberto com sacos ráfia e solo descoberto. E dois tipos de manejo hídrico: a) cultivo sem restrição hídrica no ciclo da cultura, e b) com restrição hídrica de 10 dias durante a fase de floração. As temperaturas do solo e a umidade do solo foram monitoradas por meio de termistos e por refletômetro de conteúdo de água automáticos. O manejo hídrico foi realizado com base na evapotranspiração da cultura. As maiores e menores temperaturas do solo foram observadas nos tratamentos cobertos com sacos ráfia e com palha, respectivamente. Os cultivos com solo coberto apresentaram menor disponibilidade hídrica no solo devido a retenção de parte da água nas coberturas. A restrição hídrica acarretou perda na produtividades de grãos de 93,3\%, 92,6\% e 84,3\% comparado aos tratamentos sem restrição que foram de 1487,1396 e $861 \mathrm{~kg} \mathrm{ha}^{-1}$ nos tratamentos com solo descoberto, solo coberto com palha e plásticos, respectivamente. A mesma tendência foi observada para eficiencia de uso da água. As coberturas de solo não contribuiram para minimizar o efeito negativos das restrições hídricas sobre a produtividade da cultura e a eficiencia de uso da água.
\end{abstract}

Palavras-chave: déficit hídrico, produtividade de grãos e umidade do solo.

\section{YIELD AND WATER USE EFICIENCY IN BEAN CROPS (PHASEOLUS VULGARIS} L.) UNDER DIFFERENT SOIL COVERS SUBMITTED TO WATER RESTRICTION

\footnotetext{
${ }^{1}$ Mestre em Agronomia, Centro de Ciências Agrárias, Universidade Federal de Alagoas- UFAL, Rio Largo - AL, jedmilsonbrito@ig.com.br

${ }^{2}$ Professor doutor, Faculdade de Ciências Agrárias, UFGD, Dourados - MS, alexsandroalmeid@ufgd.edu.br ${ }^{3}$ Professor doutor, Departamento de Ciências Ambientais, UFRRJ, Seropédica - RJ, gblyra@gamil.com

${ }^{4}$ Professor doutor, Centro de Ciências Agrárias, UFAL, Rio Largo - AL, ricardo_ceca@hotmail.com, iedoteodoro@ig.com.br, leonaldojs@yahoo.com.br
} 


\begin{abstract}
The objective of this work was evaluate the effect of utilization of different soil covers under grain yield and water use efficiency in bean cropps submitted to water restriction. The field experiment was conducted in delineation in blocks randomized with fatorial of $3 \times 2$. Three types of soil managment: soil covered with straw, soil covered with plastic and bare soil. Two types of water managment: a) crop without water restriction in whole crop cycle, and b) with water restriction of 10 days in flowering stage. Soil temperature and soil water were monitored by automated soil sensors. Highest and slowest soil temperatures values were observed in the treatment covered by plastic and straw, respectively. Covered crops showed lower water disponibility in the soil due to the retention by covers of some part of water. Water restriction provoque reduction in the grain yield of $93,3 \%, 92,6 \%$ and $84,3 \%$ compared to treatments well wattered which were 1487, 1396 and $861 \mathrm{~kg} \mathrm{ha}^{-1}$ in the bare soil, soil covered with straw and plastic, respectively. The same tendency were observed for water use efficiency. Soil covers not contributed to minimize the negative effects from water restriction under the graind yield and water use efficiency.
\end{abstract}

Keywords: water deficit, grain yield and soil water content.

\section{INTRODUÇÃO}

A região nordeste do Brasil é uma das principais produtoras de feijão comum (Phaseolus vulgaris L.). Em Alagoas seu cultivo é realizado em todo o estado. Nessa região, os cultivos são em condições de sequeiro, com a realização da semeadura no inicio da estação chuvosa nos meses de abril-maio e a colheita entre julho-agosto. Os volumes totais anuais de chuva nas regiões produtoras do Estado variam de 800 a $1800 \mathrm{~mm}$, com aproximadamente $70 \%$ desse total concentrado na estação de cultivo do feijoeiro (SOUZA et., 2004). Esses volumes são mais do que suficiente para a obtenção de boas produtividades (300 a $500 \mathrm{~mm}$, DOORENBOS e KASSAN, 1979). Porém muitas vezes essa chuva não é bem distribuida, sendo frequente a ocorrência de veranicos nas diferentes fases da cultura. Veranicos de 5 a 7 dias tem alta probabilidade de ocorrência (5 a 85\%) durante a estação chuvosa, principalmente nos anos com influência do evento El Niño (CARVALHO et al., 2013).

A ocorrência desses veranicos é o principal fator que contribui para as perdas de produtividades do feijoeiro no estado de Alagoas. Sendo que, a magnitude das perdas varia em função de sua intensidade nas diferentes fases fenológicas (BIZARI et al, 2009; CALVACHE et al., 1998; STONE et al.,
2006). As fases mais sensíveis ao defícit hídrico são as de florescimento e de enchimento de grãos. Para diminuir ou amenizar os efeitos do estresse hídrico sobre a produtividade é necessário a adoção de técnicas conservacionais que aumentem a eficiencia de uso da água e diminua as perdas de água pela cultura (LYRA et al., 2010).

O sistema plantio direto (SPD) em função da cobertura morta presente na superfície do solo proporciona economia de água na cultura do feijoeiro (STONE E MOREIRA, 2000; LI et al., 2008; SHEN et al, 2012;). Cultivos com SPD apresentaram menores valores de evapotranspiração da cultura e maior eficiencia de uso da água quando comparados a cultivos com solo descoberto (STONE et al., 2006; BIZARI et al., 2009). Isso se deve aos benefícios proporcionados pelo SPD: aumento da retenção de água, aumento da capacidade de infiltração melhorias das propriedades físicas do solo, diminuição da temperatura do solo, e principalmente, devido a diminuição da evaporação da água na sua superfície (LI et al., 2008).

O SPD é uma técnica consagrada em regiões onde se cultivam duas ou mais safras por ano, devido a necessidade de formação de palha ano todo que mantem o solo protegido permanentemente. Em Alagoas, geralmente se cultiva apenas uma safra de sequeiro por ano. 


\section{PRODUTIVIDADE E EFICIÊNCIA DE USO DA ÁGUA EM CULTIVO DE FEIJÃO SOB DIFERENTES COBERTURAS DO SOLO SUBMETIDO À RESTRIÇÃO HÍDRICA}

Nesse caso, a palhada de uma cultura é degradada até o próximo plantio, não sobrando resíduos para cobrir a superfície do solo. Porém existe diversas opções de cobertura de solo, dentre elas, a utilização de plásticos como é feito no cultivo de hortaliças e o uso de palhadas.

Nas pequenas propriedades da região, as atividades rurais são de subsistencia onde se pratica a agricultura e criação de animais. Existindo disponibilidade de material para cobertura das capineiras e sacos de ráfia de ração animal e produtos agrícolas. Com isso, o objetivo do trabalho foi avaliar o efeito da utilização de diferentes coberturas de solo na produtividade e eficiencia de uso da água em cultivo de feijão submetido a restrição hídrica na fase florescimento.

\section{MATERIAL E MÉTODOS}

O experimento foi conduzido na área experimental do Centro de Ciências Agrárias da Universidade Federal de Alagoas, Rio Largo, Alagoas (09 28' S, 35 49' e 127 m de altitude). O solo é classificado como Latossolo Amarelo Coeso Argissólico.

O experimento foi conduzido em blocos ao acaso em fatorial de 3 x 2 , com cinco repetições. $\mathrm{O}$ cultivo do feijão foi avaliado sob 3 sistemas de cobertura do solo e dois regimes de manejo de irrigação: cultivo sem restrição hídrica durante todo o ciclo, utilizando irrigação complementar quando necessário; cultivo com restrição hídrica por dez dias durante a fase de floração, iniciando-se a restrição 36 dias após a semeadura (DAS). Os três sistemas de cobertura do solo foram: solo descoberto, solo coberto com sacos ráfia de coloração branca e solo coberto com palha de capim. O tamanho das parcelas foi de $100 \mathrm{~m}^{2}$.

Foi utilizado a variedade Pérola da EMPRAPA, de crescimento determinado. No dia 16 de dezembro de 2004 foi realizado a semeadura mecanicamente a $0,04 \mathrm{~m}$ de profundidade semeando-se de 13 a 15 sementes por metro, no espaçamento de $0,5 \mathrm{~m}$ entre linhas (estande de 240.000 plantas por hectare). A adubação de fundação foi feita com base na análise química do solo (Tabela 1), utilizando-se $450 \mathrm{Kg} \mathrm{ha}^{-1}$ da fórmula 04-10-13 (num total de $100 \mathrm{Kg}$ de Sulfato de Amônio, $250 \mathrm{Kg}$ de Superfosfato simples e $100 \mathrm{Kg}$ Cloreto de potássio, por hectare). Aos 20 DAS foi realizada uma adubação de cobertura aplicando-se $100 \mathrm{Kg}$ $\mathrm{ha}^{-1}$ de uréia. Quando necessário, controlaram-se as plantas nativas e as pragas através de capinas manuais e inseticidas químicos, respectivamente.

Tabela 1. Resultado da análise química do solo. Prof.-profundidade, $\mathrm{pH}$ - Potencial de hidrogenação, $\mathrm{P}$ - fósforo, $\mathrm{Ca}$ - cálcio, $\mathrm{Mg}$ - magnésio, $\mathrm{K}$ - potássio, $\mathrm{SB}$ - soma de bases, $\mathrm{Al}$ - alumínio, $\mathrm{H}+\mathrm{Al}$ - hidrogênio mais alumínio, $\mathrm{T}$ - capacidade de troca de bases, $\mathrm{m}$ - saturação por alumínio v - saturação por bases.

\begin{tabular}{cccccccccccc}
\hline Prof. & $\mathrm{pH}$ & $\mathrm{P}$ & $\mathrm{Ca}$ & $\mathrm{Mg}$ & $\mathrm{K}$ & $\mathrm{SB}$ & $\mathrm{Al}$ & $\mathrm{H}+\mathrm{Al}$ & $\mathrm{T}$ & $\mathrm{m}$ & $\mathrm{v}$ \\
\hline $\mathrm{cm}$ & & $\ldots \mathrm{mg} \mathrm{dm}^{-3} \ldots$ & $\ldots \ldots \ldots \ldots \ldots \ldots \ldots \ldots \ldots . \mathrm{cmolc} \mathrm{dm}^{-3} \ldots \ldots \ldots \ldots \ldots \ldots \ldots \ldots \ldots \ldots$ & $\ldots \ldots \ldots \ldots \ldots \ldots \ldots \ldots$ \\
\hline $0-20$ & 5,8 & 16 & 2,5 & 2,07 & 0,05 & 4,59 & 0,05 & 3,87 & 8,5 & 1,1 & 55,40 \\
\hline
\end{tabular}

Utilizou-se um sistema de irrigação de aspersão convencional com aspersores em espaçamento de 12 x $12 \mathrm{~m}$, pressão de serviço em torno de 18 m.c.a, vazão média de $1,10 \mathrm{~m}^{3} \mathrm{~h}^{-}$ ${ }^{1}$ por aspersor, e lâmina bruta aplicada de $7,6 \mathrm{~mm}$ $\mathrm{h}^{-1}$. Para o tratamento Irrigação plena com solo descoberto a perda de água para a atmosfera foi considerada como evapotranspiração da cultura $\left(\mathrm{ET}_{\mathrm{c}}\right)$ e no solo coberto com palha ou plástico transpiração (T), devido a evaporação da água do solo coberto ser desprezível. Nessas condições ET $_{c}$ e $\mathrm{T}$ representam a perda potencial de água da cultura.

A evapotranspiração da cultura diária $\left(\mathrm{ET}_{\mathrm{c}}, \mathrm{mm} \mathrm{d}^{-1}\right)$ e a transpiração $\left(\mathrm{T}, \mathrm{mm} \mathrm{d}^{-1}\right)$ foram determinadas pelas seguintes equações (Allen et al., 1998):

$$
E T_{c}=K_{c} E T_{o}
$$

(O1) 


$$
T=K_{c b} E T_{o}
$$

em que: $\mathrm{ET}_{\mathrm{c}}$ é a quantidade de água perdida do sistema solo-planta para a atmosfera e $\mathrm{T}$ é a água que foi utilizada nos diversos processos metabólicos necessários ao crescimento e desenvolvimento das plantas.

$\mathrm{Na}$ determinação da evapotranspiração de referência diária $\left(\mathrm{ETo}, \mathrm{mm} \mathrm{d}^{-1}\right)$ utilizou-

$$
R n=-68,459+0,688 R g
$$

Os elementos climáticos necessários à estimativa de ETo foram coletados por uma estação meteorológica automática (Micrologger -21 XL, Campbell Scienntifc, Logan, Utah). Em intervalos de 10 minutos, os seguintes elementos meteorológicos foram medidos temperatura $(\mathrm{T}$, ${ }^{\circ} \mathrm{C}$ ) e umidade relativa (UR, \%) do ar, velocidade do vento a $2 \mathrm{~m}$ de altura $\left(\mathrm{u}_{2}, \mathrm{~m} \mathrm{~s}^{-1}\right)$, precipitação pluvial $(\mathrm{P}, \mathrm{mm})$, a $1,5 \mathrm{~m}$ de altura e a radiação solar. Além desses, foram coletados os extremos (máxima e mínima) diários da temperatura e umidade relativa do ar.

As variações nas características da vegetação e na cobertura média do solo durante os estádios de desenvolvimento resultam em mudanças no $\mathrm{K}_{\mathrm{c}}$ e $\mathrm{K}_{\mathrm{cb}}$. O boletim FAO-56 divide o desenvolvimento da cultura em quarto diferentes estádios: inicial, crescimento, intermediário e final. Os comprimentos médios dos estádios para o feijoeiro em condições de clima tropical são apresentados no próprio boletim. Porém, recomenda-se que sejam ajustados valores locais para as variedades avaliadas. Ajustaram-se os coeficientes para as se 0 modelo de Penman-Monteith parametrizado no boletim FAO-56 (ALLEN et al., 1998).

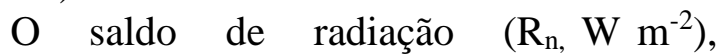
utilizado na equação da ETo, foi estimada através de uma relação linear, com dados locais, entre $R_{n}$ medido na grama (cultura de referência) e radiação global $\left(\mathrm{R}_{\mathrm{g}}, \mathrm{W} \mathrm{\textrm {m } ^ { - 2 }}\right)$ pela seguinte equação:

$\operatorname{com} R^{2}=0,947$

condições locais, considerando um ciclo médio de 70 dias para a variedade de feijão avaliada, distribuído em 13, 19, 25 e 13 dias para os estádios inicial, de crescimento, intermediário e final, respectivamente.

$\mathrm{O}$ valor médio padrão de $\mathrm{K}_{\mathrm{c}}$ para o estádio inicial $(0,4)$, intermediário $(1,15)$ e final $(0,35)$ para um clima sub-úmido, com média de URmín de $45 \%$ e velocidade média de u2 de calma a moderada $\left(2 \mathrm{~m} \mathrm{~s}^{-1}\right)$ tabelados no boletim FAO56 foram ajustados as condições edafoclimáticas e as características da cultura durante o período experimental, como recomendado por Allen et al. (1998). Procedeu-se o ajuste de $K_{c}$ inicial tabelado em função do intervalo de tempo entre eventos de chuva e sua magnitude e do poder evaporante da atmosfera (ETo). Esse ajuste foi baseado nos dados médios observados no estádio inicial utilizando o método gráfico apresentado no boletim FAO-56. No ajuste de $K_{c}$ para os estádios intermediário e final as condições climáticas e as características da cultura, a seguinte equação foi utilizada (ALLEN et al., 1998).

$$
K_{c}=K_{c(t a b)}+\left[0,04\left(u_{2}-2\right)-0,004\left(U R_{\min }-45\right)\right]\left(\frac{h}{3}\right)^{0,3}
$$

em que, $K_{c(t a b)}$ é o valor de $K_{c}$ no estádio intermediário ou final tabelado no FAO-56; u2 $\left(\mathrm{m} \mathrm{s}^{-1}\right)$ é o valor médio do período (intermediário ou final) para a velocidade diária do vento a $2 \mathrm{~m}$ de altura; $\mathrm{UR}_{\text {mín }}(\%)$ é o valor médio do período (intermediário ou final) para a umidade relativa do ar mínima diária e $\mathrm{h}(\mathrm{m})$ é a altura média da cultura durante o estádio intermediário ou final.
A curva de $K_{c}$ para todo o ciclo foi determinada interpolando-se os coeficientes ajustados para os estádios inicial, intermediário e final em função dos comprimentos de todos os estádios de desenvolvimento. Os valores de $\mathrm{K}_{\mathrm{c}}$ ajustados foram: inicial $(1,0)$, intermediário $(1,14) \mathrm{e}$ final $(0,32)$, sendo que para a determinação do 
PRODUTIVIDADE E EFICIÊNCIA DE USO DA ÁGUA EM CULTIVO DE FEIJÃO SOB DIFERENTES COBERTURAS DO SOLO SUBMETIDO À RESTRIÇÃO HÍIDRICA

$\mathrm{K}_{\mathrm{c}}$ na fase de crescimento foi feito à interpolação.

De forma análoga a $K_{c}, K_{c b}$ tabelado $\left(\mathrm{K}_{\mathrm{cb}(\mathrm{tab})}\right)$ no boletim FAO-56 para os estádios intermediário $(1,1)$ e final $(0,25)$ foram ajustado às condições edafoclimáticas do local e período experimental utilizando a eq. 09. Contudo, ao invés de $K_{c}$ e $K_{c(t a b)}$ considerou-se nessa equação $K_{c b}$ e $K_{c b(t a b)}$. No caso de $K_{c b}(0,15)$ no estádio inicial não existe necessidade correção, devido a maior partição da perda de água pelo sistema nessa fase ser na forma de evaporação da água do solo. Os valores de $\mathrm{K}_{\mathrm{cb}}$ ajustados foram: intermediário $(1,09)$ e final $(0,23)$, sendo que para os valores de $K_{c b}$ na fase de crescimento foi feito à interpolação dos valores de $\mathrm{K}_{\mathrm{cb}}$ inicial $\mathrm{e}$ intermediário.

Para o Tratamento semi-estressado foram considerados a evapotranspiração real da cultura diária $\left(E T_{\mathrm{r}} \mathrm{mm} \mathrm{d}^{-1}\right)$ e tranpiração real $\left(\mathrm{T}_{\mathrm{r}} \mathrm{mm} \mathrm{d}^{-}\right.$ ${ }^{1}$ ), para solo descoberto e solo com cobertura, respectivamente e estas determinados pelas equações:

$$
\begin{aligned}
& E T_{r}=K_{s} E T_{c} \\
& \text { e } \\
& T_{r}=K_{s} T
\end{aligned}
$$

Sendo necessário fazer a ponderação pelo $\mathrm{K}_{\mathrm{s}}$, (coeficiente de redução por déficit de água no solo) que foi determinado pela seguintes equações.

$$
\begin{aligned}
K_{s} & =\ln (A D+1) / \ln (101) \\
A D & =100\left(A-A_{p m p}\right) /\left(A_{c c}-A_{p m p}\right)
\end{aligned}
$$

em que, água disponível (AD), água real disponível (A), água disponível no ponto de murcha (Apmp) e água disponível na capacidade de campo (Acc).

$$
\text { Se } A \geq A_{c c} ; K_{s}=1
$$

Em que, coeficiente de redução por déficit de água no solo $\left(\mathrm{K}_{\mathrm{s}}\right)$. $\mathrm{O}$ armazenamento de água do no ponto de murcha permanente (Apmp) foi de 41,4 $\mathrm{mm}$ e na capacidade de campo $\left(\mathrm{A}_{\mathrm{cc}}\right)$ foi de $69,2 \mathrm{~mm}$, determinados pelo Laboratório de
Física do Solo da UFAL, pelo método da panela de pressão.

As medidas de umidade do solo foram obtidas através de sensores automáticos, refletômetro de conteúdo de água (CS616 Water Content Reflectometrs, Campbell Scientific, Inc.), ligados a um sistema de aquisição (Micrologger - 21 XL, Campbell Scienntifc, Logan, Utah), programado para fazer medidas a cada 10 segundos e armazenar média a cada hora e ajustados por uma equação polinomial usando dados locais.

As medidas de temperaturas do solo foram obtidas utilizando-se termistos automáticos (Model 107, Temperature Probe) ligados a um sistema de aquisição (Micrologger - 21 XL, Campbell Scienntifc, Logan, Utah), programado para fazer medidas a cada 10 segundos e armazenar média a cada hora. Em quatro dias próximo do meio dia e em duas profundidades, analisaram-se as variações de temperatura do solo em função dos tipos de coberturas.

Para a determinação da produtividade de grãos, colheram-se quatro metros lineares de cada parcela correspondente à linha central da parcela, em seguida determinou-se a média do peso dos grãos de todas as parcelas de cada tratamento e esta foi considerada como a produtividade média da cultura.

\section{RESULTADOS E DISCUSSÃO}

A época, em que foi realizado o experimento, é a de maior incidência de radiação e de maiores temperaturas do ar na região em estudo (SOUZA et al., 2004). Durante todo o ciclo do feijoiero, a ETo total foi de $360 \mathrm{~mm}$, numa média de $5,5 \mathrm{~mm} \mathrm{~d}^{-1}$ (Figura 1) e a ETc total foi de $273 \mathrm{~mm}$. Enquanto a precipitação total foi de apenas $115 \mathrm{~mm}$. A necessidade de água do feijoeiro com ciclo de 60 a 120 dias varia entre 300 a $500 \mathrm{~mm}$ para obtenção de alta produtividade (DOORENBOS e KASSAN, 1979; CUNHA et al., 2013). Para tanto, nos cultivos sem restrição hídrica aplicou-se um total de $261 \mathrm{~mm}$ via irrigação (Tabela 2). Durante o período de 37 a 47 DAS, em que os tratamentos SE foram submetidos ao estresse hídrico, a ETo total foi de aproximadamente $60 \mathrm{~mm}$ (Figura 1). 


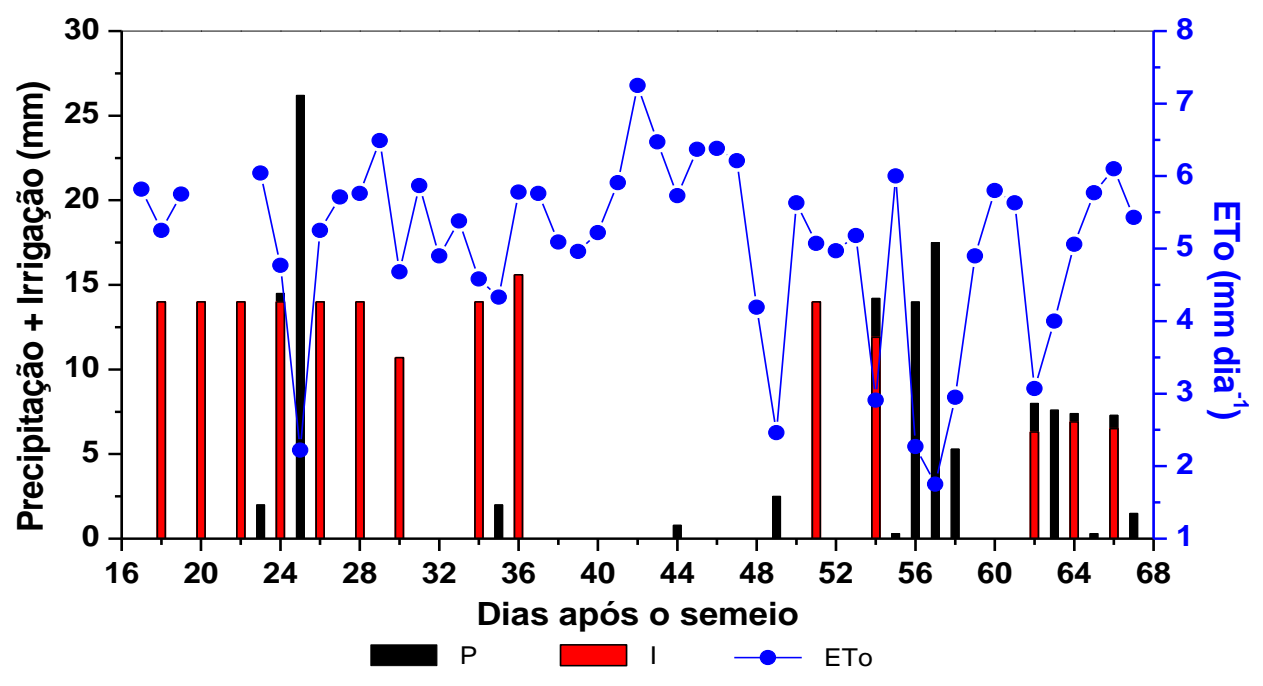

Figura 1. Valores de precipitação (P), irrigação (I) e evapotranspiração de referência (ETo), observadas durante o experimento nos tratamentos semi-estressado (SE) com restrição hídrica na fase de florescimento (37 a 47 dias após a semeadura, DAS).

Ao comparar os cultivos sem e com restrição hídrica na fase de florescimento, observou-se que nos tratamentos com solo descoberto, a ETr foi semelhante a ETc nos períodos sem estresse hídrico (Figura 2.a). No período antes da restrição, os valores foram em torno de
6,0 $\mathrm{mm} \mathrm{d}^{-1}$. No período depois esses valores foram menores, comum ao final de ciclo da cultura devido ao menor valor de Kc $(0,51)$. Durante a restrição, a ETc foi em média $1,0 \mathrm{~mm} \mathrm{~d}^{-1}$ maior do que a ETr. Essa tendência também foi observada no tratamento coberto com palha (Figura 2.b).






\section{PRODUTIVIDADE E EFICIÊNCIA DE USO DA ÁGUA EM CULTIVO DE FEIJÃO SOB DIFERENTES COBERTURAS DO SOLO SUBMETIDO À RESTRIÇÃO HÍDRICA}

Figura 2. Perda de água pela cultura para os tratamentos com e sem restrição na fase de florescimento, em função dos dias após a semeadura (DAS). a) Evapotranspiração da cultura $\left(E_{c}\right)$ e evapotranspiração real $\left(E T_{r}\right)$ para solo descoberto; b) Transpiração potencial (T) e transpiração real $\left(\mathrm{T}_{\mathrm{r}}\right)$ para solo coberto com palha; c) $\mathrm{T}$ e $\mathrm{T}_{\mathrm{r}}$ para solo coberto com com sacos de ráfia.

Todos os tratamentos receberam as mesmas laminas de irrigação nos periodos que não coincidiram com fase de florescimento (37 a 47 DAS). Entretanto, apenas no tratamento com solo descoberto se observou que a umidade permaneceu próximo a capacidade de campo, durante os primeiros 36 DAS (Figura 3). Nos tratamentos com os solos cobertos foram observados valores de umidade inferiores à capacidade de campo logo aos 27 DAS. Durante a restrição hídrica (37 a 47 DAS), a umidade do solo nos tratamentos com solo descoberto e com solo coberto com palha estavam na CC no dia 37 DAS, enquanto, no tratamento com solo coberto com plástico a umidade já estava com apenas $30 \%$ da AD (água disponível). No meio do período de restrição (44 DAS), as frações de água disponível nos dois tratamentos com solos cobertos já haviam sido esgotadas. Ao passo que, no tratamento descoberto utilizou $50 \%$ da AD. Mesmo com a ocorrência de precipitações e realização de irrigações após a restrição (51 a 68 DAS) foram observados valores inferiores a $70 \%$ da $\mathrm{AD}$ nos tratamentos com solos cobertos. No ciclo da cultura, a AD foi inferior a $60 \%$ durante 9,13 e 26 dias nos tratamentos com SN, SCPAL e SCPLAS, respectivamente.

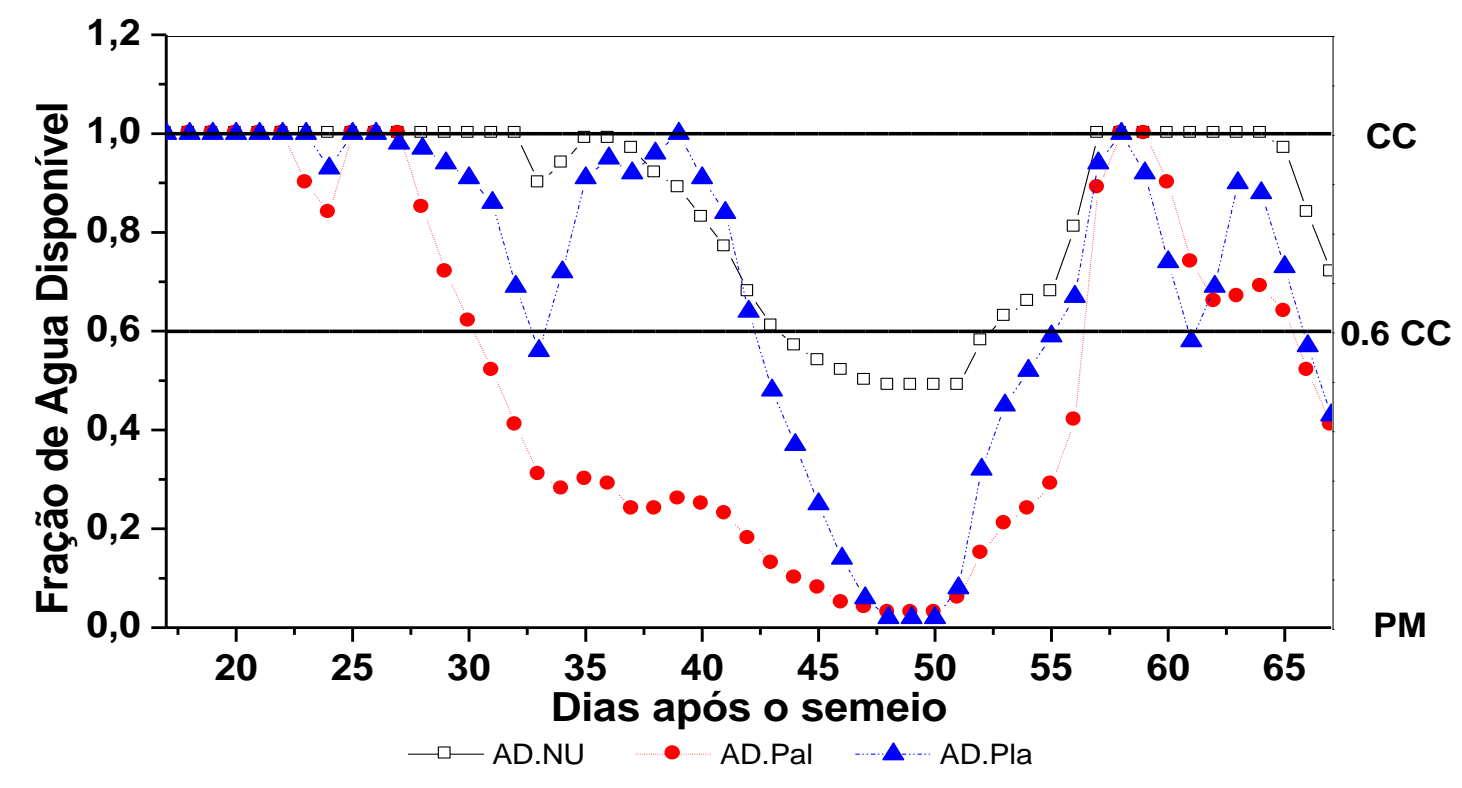

Figura 3. Fração de Água disponível (AD), água disponível na capacidade de campo (CC), água disponível 40\% abaixo da capacidade de campo (0,6 CC), umidade no ponto de murcha permanente (PM), em solo descoberto (AD Nu), coberto com palha (AD Pal) e solo coberto com plástico (AD Pla).

De forma geral foi constatado menor disponibilidade hídrica nos tratamento com os solos cobertos, contrariando muitos resultados de outras pesquisas que relatam maior conservação da umidade em solos cobertos (BIZARI et al., 2009; SHEN et al., 2012). Isso deve ter acontecido devido a menor infiltração de água no solo nesses tratamentos, pois parte da água foi retida pelas coberturas e perdida diretamente para a atmosfera (STONE e MOREIRA, 2000; SILVA et al., 2006). Essa perda foi maior onde foi coberto com o plástico que tem baixa permeabilidade. Segundo LYRA et al. (2010), em eventos fracos de precipitação 
$(<7 \mathrm{~mm})$ a cobertura morta absorve a maior parte da água que se perde diretamente para a atmosfera, sem que a água chegue ao solo. Como no experimento, os eventos de chuva foram fracos e as lâminas de irrigação (10 a 15 mm cada, aplicadas por sistema de aspersão) foram pequenas, concluisse que a maior dessa água foi retida pelas coberturas do solo.

As temperaturas do solo variaram de acordo com a profundidade e com o tipo de cobertura do solo. Observou-se um gradiente negativo de calor com o aumento da profundidade. $\mathrm{Na}$ profundidade de $10 \mathrm{~cm}$ (Figura 4.B), os valores de temperaturas do solo foram em média $2{ }^{0} \mathrm{C}$ menores do que as temperaturas na profundidade de $5 \mathrm{~cm}$ (Figura 4.A), nos tratamentos com solo coberto com plástico e solo descoberto. Já no solo coberto com palha, essa variação é em média $1^{0} \mathrm{C}$ menor. A palha parece ser um bom isolante térmico, pois nos tratamentos cobertos com palha as temperaturas do solo nas duas profundidades avaliadas foram menores que nos outros tratamentos. A influencia da cobertura do solo depende do clima da região, em regiões de clima frio a palha contribui para manter o calor no solo e aumentar a temperatura (LI et al., 2008), e diminuir nas regiões mais quentes (SALTON E MIELNICZUK, 1995; FURLANI et al., 2008). Na profundidade mais superficial, a temperatura do solo no tratamento coberto com saco plástico foi em média de 1 a $2{ }^{0} \mathrm{C}$ maior do que no solo descoberto. O saco deve evitar a dissipação do calor nas horas mais frias do dia. Porém essa influência é mais acentuada nas camadas mais superficiais, pois na profundidade de $0,10 \mathrm{~m}$ em ambos os tratamentos, as temperaturas foram muito próximas. Segundo FURLANI et al. (2008), essa variação na temperatura nos solos brasileiros não afeta o crescimento das culturas.

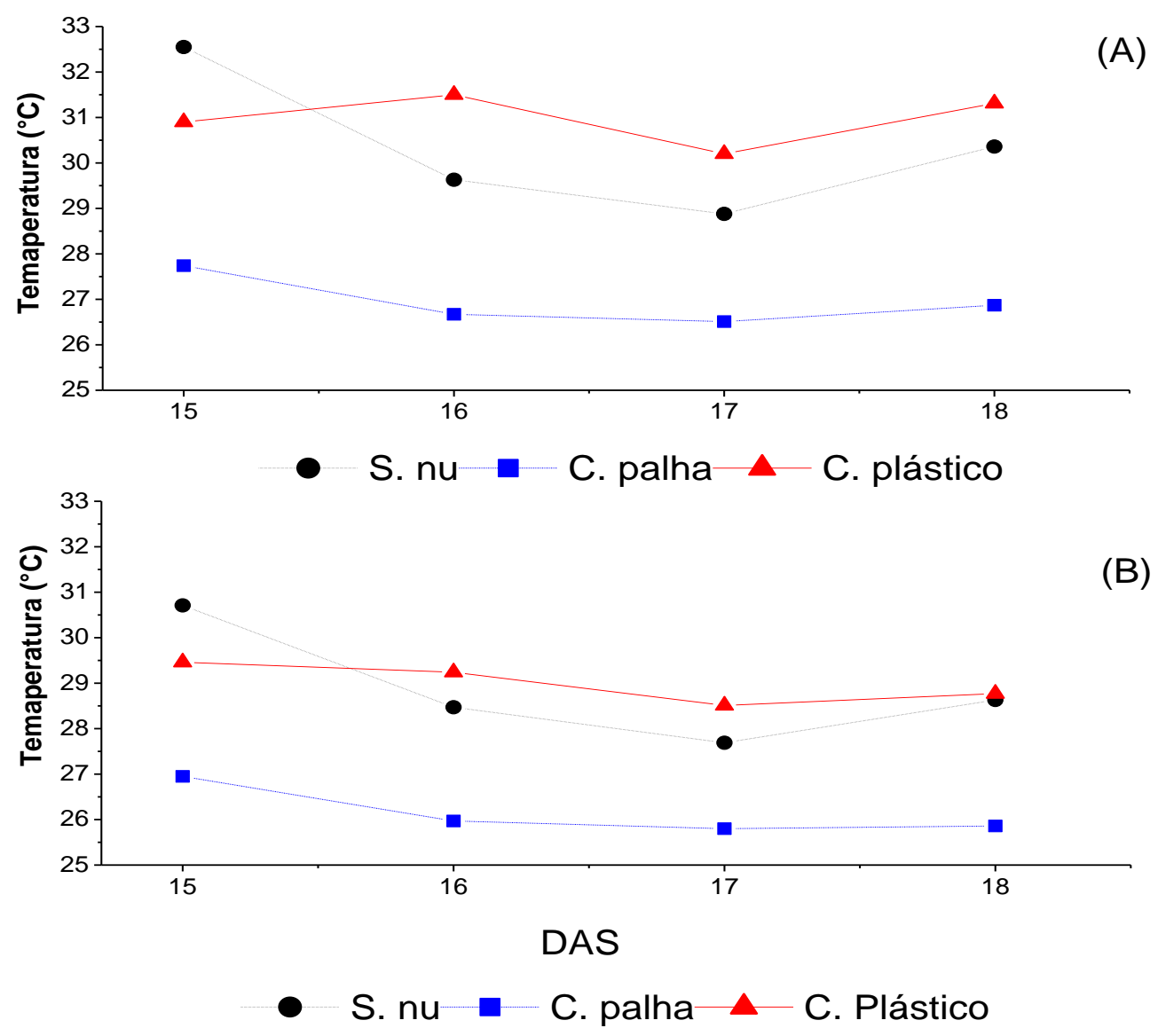

Figura 4. Temperaturas dos solos nas profundidades de $5,0 \mathrm{~cm}$ (A) e de $10 \mathrm{~cm}$ (B) nos tratamentos semi-estressado com diferentes coberturas de solo. 


\section{PRODUTIVIDADE E EFICIÊNCIA DE USO DA ÁGUA EM CULTIVO DE FEIJÃO SOB DIFERENTES COBERTURAS DO SOLO SUBMETIDO À RESTRIÇÃO HÍDRICA}

A restrição hídrica na fase de florescimento reduziu drasticamente as produtividades de grãos (Tabela 2). Acarretando redução de $93,3 \%, 92,6 \%$ e $84,3 \%$ quando comparado as produtividade de grãos obtidas nos cultivos sem restrição que foram de 1487 , 1396 e $861 \mathrm{~kg} \mathrm{ha}^{-1}$ nos tratamentos com solo descoberto, solo coberto com palha e plásticos, respectivamente. Durante a restrição ocorreu acentuada queda de flores e senescência de plantas, e após, a maioria das plantas não vegetaram mais e iniciaram a fase de amadurecimento. Isso acarretou a formação de poucas vagens e grãos poucos desenvolvidos.

O componente produtivo que geralmente é mais afetado pelo déficit hídrico, durante a floração, é o número de vagens por planta (FIEGENBAUN et al., 1991). Essa fase é a mais sensível do feijoeiro ao estresse hídrico
(CUNHA et al., 2013). Calvache et al. (1997) relataram perdas de $67 \%$ na produtividade em cultivos que sofreram estresse hídricos nessa fase. Esses altos níveis de perdas na produtividade inviabilizam o cultivo do feijão e ressaltam a necessidade da manutenção de umidade adequada nessa fase crítica da cultura.

A produtividade nos tratamento sem restrição foi maior naquele com solo descoberto. Isso se deve provavelmente, ao melhor aproveitamento da água aplicada, pois praticamente toda a água aplicada se infiltrou nos solos. Já nos cultivos com solo cobertos, uma quantidade significativa da água ficava retida nos materiais de cobertura. Essa perda teve maior magnitude na cobertura plástica, onde foi observado maior retenção de água na superfície do plástico.

Tabela 2. Resultados da Evapotranspiração de real $\left(\mathrm{ET}_{\mathrm{r}}{ }^{*}\right)$, transpiração real $\left(\mathrm{T}_{\mathrm{r}}{ }^{*}\right)$, produtividade de grãos e eficiência do uso da água (EUA) nos cultivos do feijoeiro cultivados com e sem cobertura do solo e submetidos ou não a restrição hídrica na fase de florescimento.

\begin{tabular}{llcccc}
\hline Restrição hídriı Manejo do Solo & $\begin{array}{c}\text { Água } \\
\text { Aplicada } \\
(\mathrm{mm})\end{array}$ & $\begin{array}{c}\mathrm{ETr}^{*}, \mathrm{~T}^{* *} \\
(\mathrm{~mm})\end{array}$ & $\begin{array}{c}\text { Produtividade } \\
\left(\mathrm{kg} \mathrm{ha}^{-1}\right)\end{array}$ & $\begin{array}{c}\text { EUA } \\
\left(\mathrm{kg} \mathrm{m}^{-3}\right)\end{array}$ \\
\hline \multirow{3}{*}{ Sem } & Descoberto & 376,40 & 273,90 & 1487,00 & 0,54 \\
& Palha & 376,40 & 247,55 & 1396,00 & 0,57 \\
& Plastico & 376,40 & 231,11 & 861,00 & 0,37 \\
\multirow{3}{*}{ Com } & Descoberto & 344,40 & 261,86 & 101,00 & 0,04 \\
& Palha & 344,40 & 211,79 & 103,00 & 0,05 \\
& Plastico & 344,40 & 170,08 & 136,00 & 0,08 \\
\hline
\end{tabular}

* Solo descoberto; ${ }^{* *}$ Cobertura com Palha ou sacos de ráfia.

No cultivo com solo descoberto foi observado menor numero de dias com umidade do solo abaixo de $60 \%$ da disponibilidade hídrica do solo. Entretanto, quanto a produtividade não houve diferença significativa, e, sobretudo, tiveram grandes perdas na produtividade. mostrando que um déficit de 8 dias na fase de florescimento já é suficiente para reduzir a níveis insatisfatórios de produtividade. $\mathrm{E}$ que as coberturas não finfluenciaram na minimização do danos.

Doorenbos e Kassam estabeleceram, para a cultura do feijoeiro, o valor da eficiência de uso da água na ordem de 0,3 a $0,6 \mathrm{~kg} \mathrm{~m}^{-3}$ quando utilizado de 300 a 500 mm no ciclo da cultura. Nos tratamentos sem restrição, as EUA foram ao redor de $0,50 \mathrm{~kg} \mathrm{~m}^{-3}$ e tendo sido aplicados $376,4 \mathrm{~mm}$ durante todo o ciclo. Em outras pesquisas no Brasil foram relatados EUA proximo de $1 \mathrm{~kg} \mathrm{~m}^{-3}$ (ANDRADE et al., 2002; BIZARI et al., 2009; CUNHA et al., 2013). Porém nos tratamento com restrição no florescimento, as EUA foram em 10 vezes menor $\left(0,06 \mathrm{~kg} \mathrm{~m}^{-3}\right)$ mesmo que tendo sido aplicado uma lamina total no ciclo de $344,4 \mathrm{~mm}$, mostrando a alta sensibilidade da cultura ao estresse hídrico na fase de florescimento.

A forma de aplicação das irrigações (aspersores de baixa pressão) e os eventos de 
chuvas fracas contribuiram para a retenção de água nas coberturas e redução da disponibilidade hídrica. Em outras situações, sistemas com aplicação da irrigação na superfície ou a aplicação de laminas maiores, os resultados podem ser contrários aos encontrados. Além do que, as coberturas propiciam maior conservação do solo. Portanto, é necessário que outros trabalhos sejam realizados para avaliar a eficiência de uso da água em outras condições.

\section{CONCLUSÃO}

Todos os cultivos com restrição hídrica, na fase de florescimento, obtiveram produtividades de grãos e eficiência de uso de água muito baixas, sendo que, as coberturas não melhoram a disponibilidade hídrica do solo e não minizaram os efeitos da restrição hídrica na fase de florescimento na produtividade do feijoeiro.

\section{REFERÊNCIAS}

ALLEN, R.G., PEREIRA, L.S., RAES, D., SMITH, M.. Crop evapotranspiration: Guidelines for computing crop water requirements. Irr. Drain. Paper 56. UN-FAO, Rome, 1998.

ANDRADE, R.S.; MOREIRA, J.A.A.; STONE, L.F.; CARVALHO, J.A. Consumo relativo de água do feijoeiro no plantio direto em função da porcentagem de cobertura morta do solo. Revista Brasileira de Engenharia Agrícola e Ambiental, Campina Grande, v.6, n.1, p.35-38, 2002.

BIZARI, D. R.; MATSURA, E. E.; ROQUE, M. W.; SOUZA, A. L. Consumo de água e produção de grãos do feijoeiro irrigado em sistemas plantio direto e convencional. Ciência Rural, Santa Maria: v.39, p.2073-2079, 2009.

CALVACHE, M.; REICHARDT, K.; BACHI, O.O.S.; DOURADO NETO, D. Deficit irrigation at different growth stage on commom bean. Scientia Agrícola, Piracicaba, n 54, 1-36, 1997.

CARVALHO, J.A.; PEREIRA J.M.;ANDRADE, M.J.B.; ROQUE, M.W.; Efeito do déficit hídrico sobre o rendimento do feijão caupi (Vigna unguiculata (L.) Walp). Ciênc. agrotec., Lavras, v.24, n.3, p.710-717, jul./set., 2000.

CARVALHO, A.L.; SOUZA, J.L.; LYRA, G.B.; PORFIRIO, A.C.S. (2013). Ocorrência de períodos secos na região de Rio Largo, Alagoas. Revista Brasileira de Meteorologia, 28(2), 173-180. Retrieved

CUNHA,P.C.R.; $\quad$ SILVEIRA, P.M.; NASCIMENTO, J.L.; ALVES JÚNIOR, J.(2013) Manejo da irrigação no feijoeiro cultivado em plantio direto. Revista Brasileira de Engenharia Agrícola e Ambiental, Campina Grande, v.17, n.7, p.735-742, 2013.

DOOREMBOS, J.; KASSAN,A.H. Field response to water. Rome: FAO, 1979. 193p. (FAO. Irrigation and drainage Paper, 33).

FIEGENBAUM, V.; SANTOS, D.S.B., MELLO, V.D.C. Influência do déficit hídrico sobre componentes e rendimento de três cultivares de feijão. Pesquisa Agropecuária Brasileira. Brasília, v.26, n.2, p.275-80, 1991.

FURLANI, C.E.A.; GAMERO, C.A; SILVA, R.P.; CORTEZ, J.W. (2008). Temperatura do solo em função do preparo do solo e do manejo da cobertura de inverno. Revista Brasileira de Ciência do Solo, Viçosa: 32(1), 375-380.

LI Q.Q., CHEN Y.H., LIU M.Y., ZHOU X.B., YU S.L., DONG B.D. (2008): Effects of irrigation and straw mulching on microclimate characteristics and water use efficiency of winter wheat in North China. Plant Production Science, 11: 161-170.

LYRA, G.B., SOUZA, J.L.; TEODORO, I.; LYRA, G.B., MOURA FILHO, G., ARAÚJO JUNIOR, R.F. Contéudo de água no solo em 
cultivos de milho sem e com cobertura morta na entrelinha na região de Arapiraca-AL. Irriga, Botucatu. v.15, n.2, p. 173-183. abril-junho 2010.

SALTON, J.C.; MIELNICZUK, J. Relações entre sistemas de preparo, temperatura e umidade de um Podzólico Vermelho-Escuro de Eldorado do Sul (RS). Revista Brasileira de Ciência do Solo, Campinas, v.19, n.2, p. 313319, 1995.

SHEN, J.Y.; ZHAO, D.D.; HAN, H.F.; ZHOU, X.B.; Li, Q.Q. Effects of straw mulching on water consumption characteristics and yield of different types of summer maize plants. PLANT SOIL ENVIRON., 58, 2012 (4): 161-166.

SOUZA, J.L.; MOURA FILHO, G.; LYRA, R.F.F. TEODORO, I.; SANTOS, E.A.; SILVA,
J.L.; SILVA， P.R.T.; CARDIM， A.H.; AMORIN, E.C. Análise da precipitação pluvial e temperatura do ar na região do tabuleiro costeiro de Maceió, AL, período de 1972-2001.

Revista Brasileira de Agrometeorologia, Santa Maria, v.12, n.1, p.131-141, 2004.

STONE, L.F.; MOREIRA, J.A.A. Efeitos do sistema de preparo do solo no uso da água e na produtividade do feijoeiro. Pesquisa Agropecuária Brasileira, Brasília, v.35, n.4, p. 835-841, 2000.

STONE, L.F.; SILVEIRA, P.M.; MOREIRA, J.A.A.; BRAZ A.J.B.P. Evapotranspiração do feijoeiro irrigado em plantio direto sobre diferentes palhadas de culturas de cobertura. Pesquisa Agropecuária Brasileira, Brasília, v.41, n.4, p. 577-582, 2006. 